\title{
Study on Sedimentary Facies and Reservoir Characteristics of Paleogene Sandstone in Yingmaili Block, Tarim Basin
}

\author{
Hanlie Cheng $\left(\mathbb{D},{ }^{1}\right.$ Jianfei Wei, ${ }^{1}$ and Zhaoyuan Cheng ${ }^{2}$ \\ ${ }^{1}$ COSL-EXPRO Testing Services (Tianjin) Co., Ltd., Tianjin 300457, China \\ ${ }^{2}$ College of Petroleum Engineering, Xi'an Shiyou University, Xi'an, Shaanxi 710065, China
}

Correspondence should be addressed to Hanlie Cheng; chenghl@cosl-expro.com

Received 9 January 2022; Accepted 16 February 2022; Published 7 March 2022

Academic Editor: Kouqi Liu

Copyright (C) 2022 Hanlie Cheng et al. This is an open access article distributed under the Creative Commons Attribution License, which permits unrestricted use, distribution, and reproduction in any medium, provided the original work is properly cited.

\begin{abstract}
Block Yingmai 7 is structurally located in the western segment of the southern margin of the Kuqa Depression in the Tarim Basin. In the foreland basin, huge continental Mesozoic and Cenozoic strata have been deposited. In recent years, the Paleogene bottom sandstone section has been the main oil and gas exploration horizon. In order to further improve the oil and gas exploration effect of the Paleogene bottom sandstone in the study area and improve the accuracy of reservoir prediction, based on the related theory of sedimentology and petrology, this paper analyzes and studies the cores obtained by drilling in the Paleogene through laboratory core analysis experiments. The study shows that the Paleogene bottom sandstone is a braided river delta sedimentary system, and the sedimentary microfacies are mainly underwater distributary channels. The sandstone type is mainly light gray lithic feldspar fine sandstone, the sandstone debris particle sorting degree is medium-good, and the roundness is sub-edge-sub-circular. The microscopic characteristics of the reservoir are large pore throat radius, low displacement pressure, mainly intergranular pores, and good pore connectivity. It is a thin-layered mesoporous, medium-permeable, large-throat, and strongly heterogeneous reservoir. Finally, a classification evaluation table of reservoirs in block Yingmai 7 is established, and it is considered that the reservoirs of types I and II are enriched areas of oil and gas resources. The research results provide evidence for the prediction of oil and gas reservoirs.
\end{abstract}

\section{Introduction}

The Tarim Basin is the largest hydrocarbon-bearing basin in China. It is a superimposed composite basin which is located between the Tianshan Mountains, Kunlun Mountains, and Altun Mountains in Xinjiang Uygur Autonomous Region [1]. The basin area is $56 \times 10^{4} \mathrm{~km}^{2}$. The ProterozoicCenozoic was developed from bottom to top in the basin, with a maximum thickness of more than $10000 \mathrm{~m}$, containing rich oil and gas resources. In the past 30 years, largescale exploration has been carried out around the Tabei uplift and the Tazhong uplift in the platform basin, the Kuqa Depression, and the southwest depression in the foreland area [2-4]. Important discoveries have been made in three areas of clastic rocks in the basin area. The clastic rock in the platform basin is the key area for oil and gas exploration in the Tarim Basin [5]. In recent years, the exploration has mainly focused on the Meso-Cenozoic continental clastic rocks in the northern Tabei area and the SilurianCarboniferous marine clastic rocks in the platform area [6-8]. The types of oil and gas reservoirs are complex, including anticlines, faulted anticlines, fault blocks, structural-stratigraphic, and structural-lithologic reservoirs [9]. The oil and gas source analysis results of the discovered oil and gas reservoirs show that the oil and gas from the Kuqa Depression are mainly distributed in the Neogene, Paleogene, Cretaceous, and Jurassic in the Luntai uplift and the Yingmaili low uplift in the western Tabei uplift and Silurian buried hill formations $[10,11]$.

The Paleogene condensate gas reservoir in the Yingmaili area is one of the earliest oil and gas reservoirs discovered in the Cenozoic in the Kuqa Depression [12-14]. Well YM9 is the first well in the area. It was completed and tested in the 4683-4690 m well section in April 1992. The $11.11 \mathrm{~mm}$ nozzle was used to obtain production, with a daily oil production of $43.6 \mathrm{~m}^{3}$ and a daily gas production of $15.7 \times 10^{4} \mathrm{~m}^{3}$, 


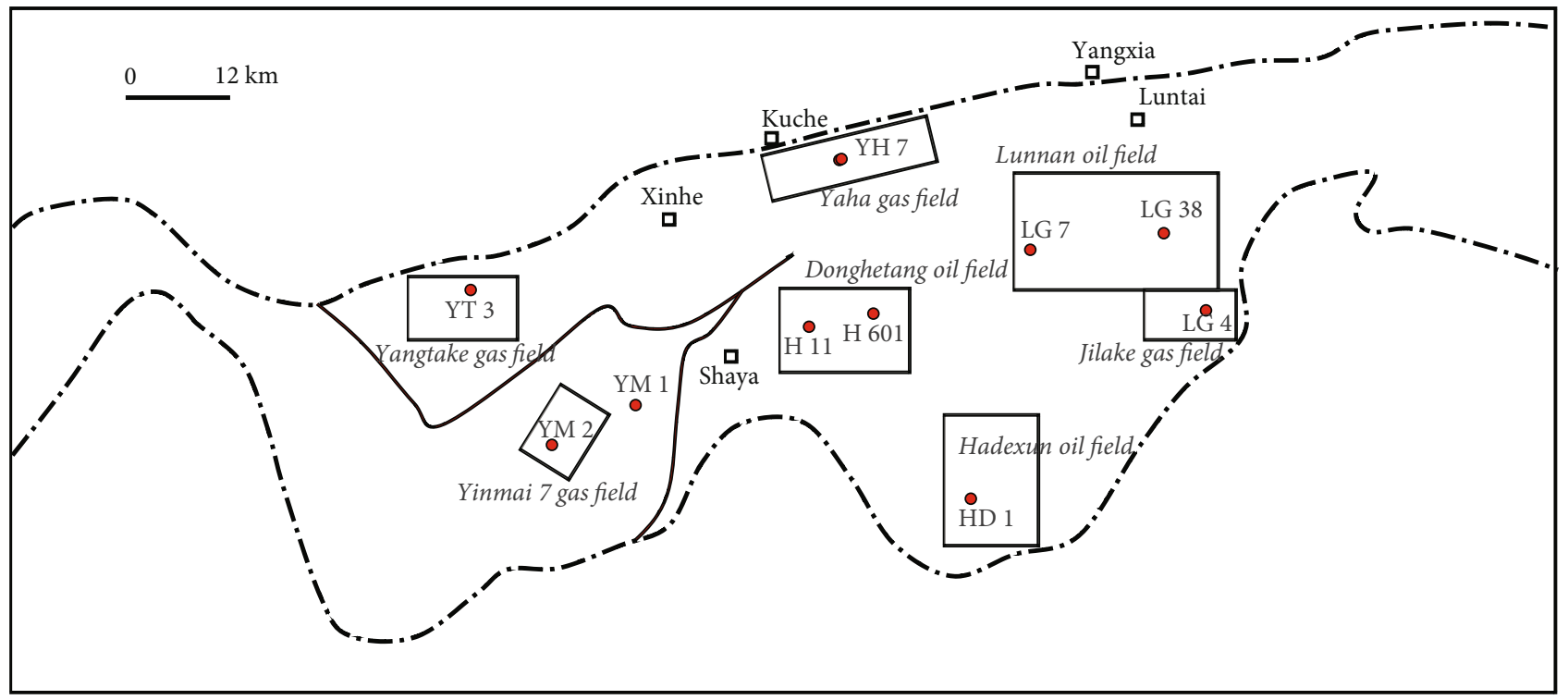

Figure 1: The structural location map of Yingmai 7 block area.

which proves that the Paleogene in the Yingmaili area has the conditions for forming oil and gas reservoirs $[15,16]$. The Yingmai 7 fault structural belt is located in the western segment of the frontal uplift belt of the Kuqa Depression in the Tarim Basin, adjacent to the Yangtake anticline to the north, and the Karayuergun structural belt to the west. The structural belt is NE-SW trending, about $70 \mathrm{~km}$ long and $10 \mathrm{~km}$ wide (Figure 1) [17]. The entire fault tectonic belt has experienced three development periods: the HercynianIndosinian period, which is dominated by strong reverse fault activities and developed a series of large thrust faults below the Cretaceous; Yanshan-Xishan early stage: after the deposition of the Genian system, fault activity was the mainstay, and a series of north-dipping normal faults developed, forming beaded anticlines and fault noses on the upper wall of the fault; Himalayan period: due to the change in the form and direction of fault activity, the Neogene strata developed thrust faults with different properties from those formed earlier, resulting in the uneven thickness of the Neogene strata on the upper and lower walls of the fault [18].

With the continuous deepening of the exploration of the Paleogene condensate gas reservoirs in the Yingmaili area, the problems of increasing difficulty in reservoir prediction and difficult reservoir identification have emerged, which have brought great challenges to the oil and gas exploration in this area. Sedimentary facies are stratigraphic units that reflect the characteristics of paleo-sedimentary environments and have certain lithology and paleobiological markers. From the lithology, structure, and paleontology of sediments (rocks), the environment and process of deposition can be judged. The concept of sedimentary facies was first put forward by Swiss A.Gressly in 1838. The analysis of sedimentary facies for oil and gas reservoirs is an important research process in oil and gas exploration. In the early stage of exploration, laboratory experiments were carried out on the Paleogene reservoir cores. However, due to the large differences in reservoir characteristics between different strata and different regions in the Yingmaili block, it is still necessary to conduct detailed analysis and research on key exploration areas. In this paper, taking the Yingmai 7 fault structural zone in the Yingmaili block as the research area, the core samples obtained through a large number of drillings and the laboratory core test method are used to analyze the sedimentary facies and reservoir characteristics of the sandstone at the bottom of the Paleogene in detail. Oil and gas exploration provides a research basis.

\section{Materials and Methods}

2.1. Stratigraphic Characteristics. The strata drilled from top to bottom in block Yingmai 7 are as follows: Quaternary in Cenozoic, Kuqa Formation, Kangcun Formation, Jidike Formation in Neogene, Paleogene, Cretaceous and Jurassic in Mesozoic Department, and the Ordovician of the Lower Paleozoic (Table 1). The main hydrocarbon-bearing intervals are the Paleogene bottom sandstone and the Cretaceous Bashijiqike Formation top sandstone.

2.2. Test Materials and Equipment. The test material comes from a large number of core samples obtained from drilling in the sandstone section at the bottom of the Paleogene in block Yingmai 7. The core samples were prepared according to the experimental method to prepare the core slices to be tested. In the thin section production process, we first select representative rock samples, wash the samples with oil, keep the vacuum state during the production process, and cut and number the produced cast thin sections. After rough grinding, fine grinding, and fine grinding, the thickness is $0.03 \mathrm{~mm}$, and it is ready for use after sticking the label.

The experimental instruments are as follows: X-ray diffractometer (D2 PHASER), grinding machine (ZHM-1B), pressing machine (ZHY-500), rock pore casting instrument (JS-5), scanning electron microscope (Thermo Quattro 


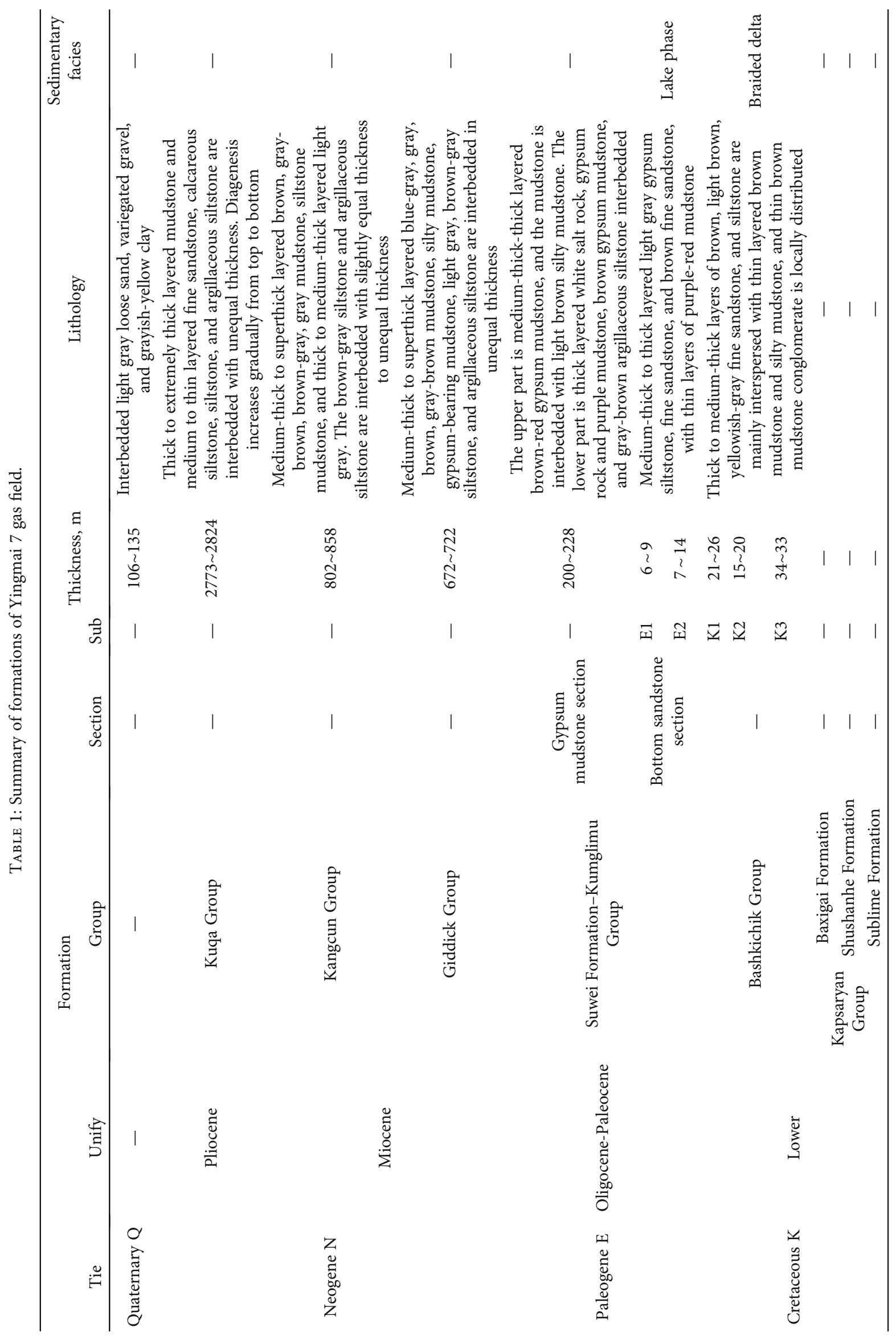




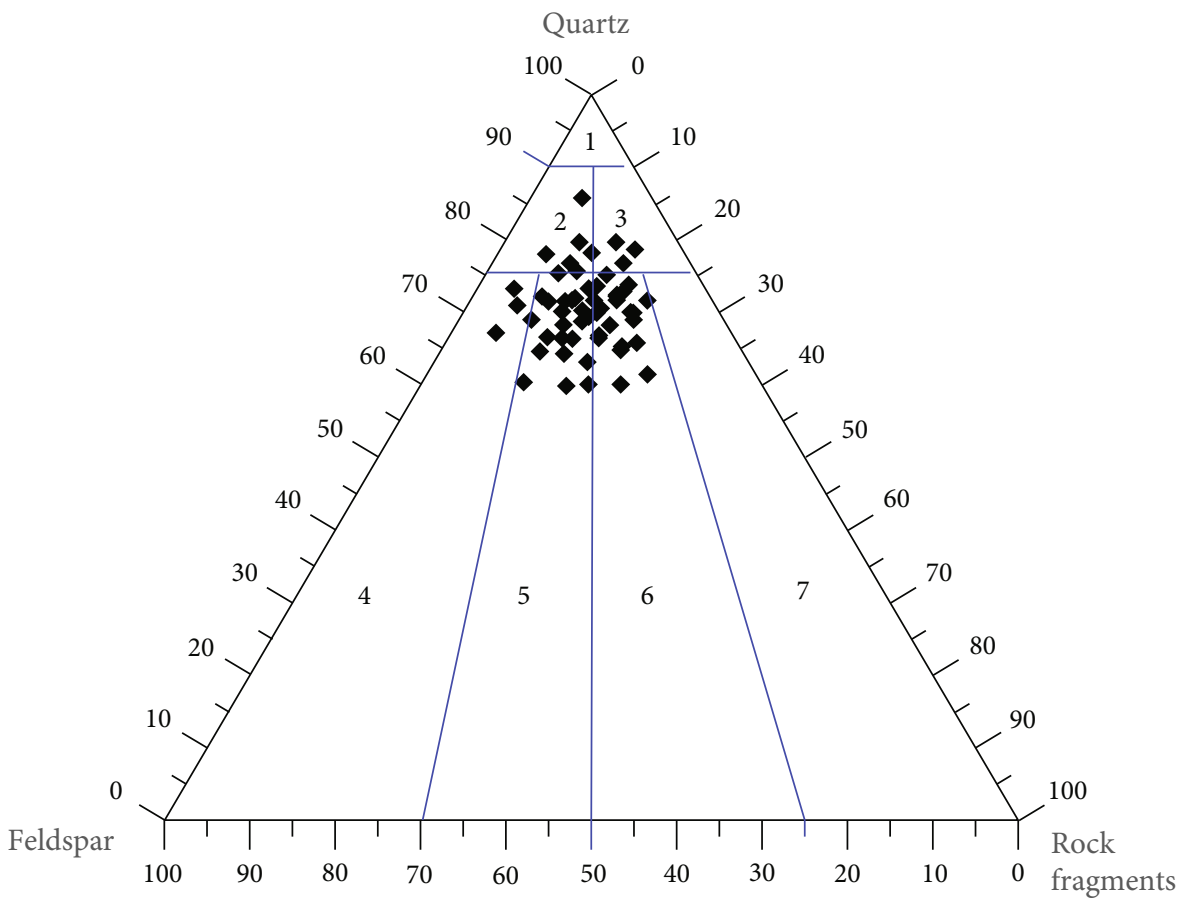

\footnotetext{
1. Quartz sandstone

2. Feldspathic quartz sandstone

3. Lithic quartz sandstone

4. Feldspathic arenite

5. Lithic feldspar sandstone

6. Feldspar lithic sandstone

7. Lithic sandstone
}

FIgURE 2: Triangle map of Paleogene sandstone composition in Yingmai 7 block.

ESEM), full diameter core permeability tester (DYX-2), core cathodoluminescence electron microscope (CL8200 MK5), rock cutting machine (DQ1-6), automatic specific surface area and pore size distribution tester (MiniX-1), Zeiss Primotech polarizing microscope, core holders, etc. Auxiliary materials include emery, epoxy resin, curing agent, coloring agent, fir glue, etc.

\section{Result}

\subsection{Characteristics of Sedimentary Facies}

3.1.1. Reservoir Petrological Characteristics. The target layer of block Yingmai 7 is the sandstone section at the bottom of the Paleogene. The rock type is mainly lithic feldspar sandstone, accounting for $54.7 \%$ of the rock type, followed by feldspar lithic sandstone and quartz sandstone, accounting for $23.2 \%$ and $22.1 \%$ of the rock type, respectively (Figure 2).

The Paleogene sandstone reservoirs in Yingmai 7 block have high quartz content, concentrated at more than $70 \%$, feldspar content at $15-20 \%$, and debris content at $10-15 \%$, reflecting that the Paleogene rock composition maturity is relatively high. The overall grain size of sandstone is mainly

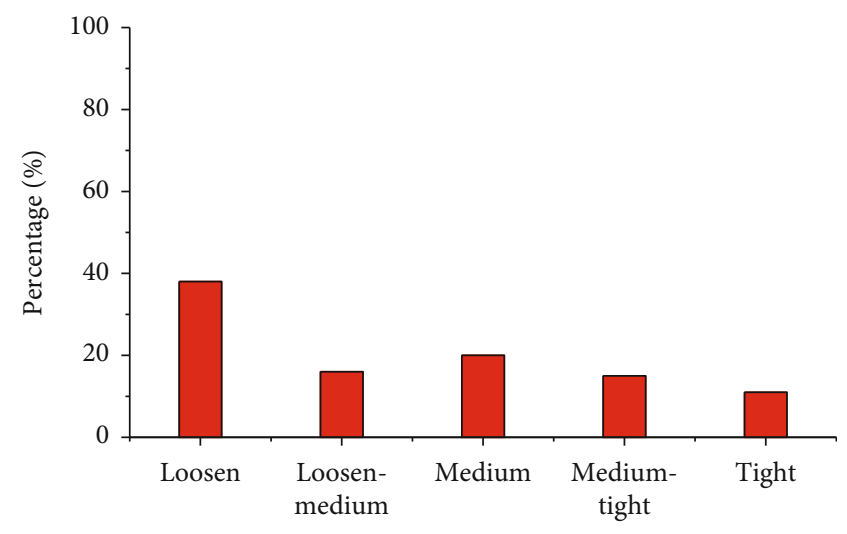

Figure 3: Histogram of frequency distribution of tightness degree of reservoir debris in block Yingmai 7.

fine sand, accounting for $69.03 \%$ of the rock particles, followed by silt, accounting for $19.12 \%$ of the rock particles. The sandstone reservoirs in the Paleogene target layer are mainly loose in density, with rounded edges and corners from subedge to subround, and the sorting grade is medium-good (Figure 3). 


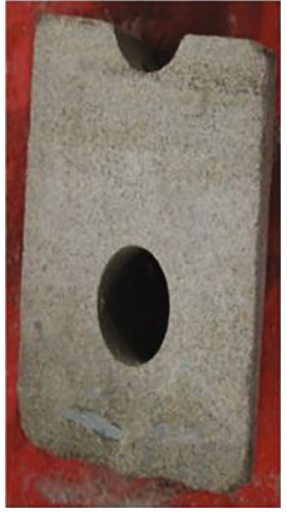

YM702

$4684.10 \mathrm{~m}$

(a)

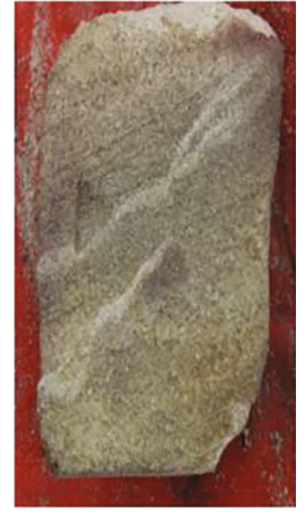

YM702

$4676.40 \mathrm{~m}$

(b)

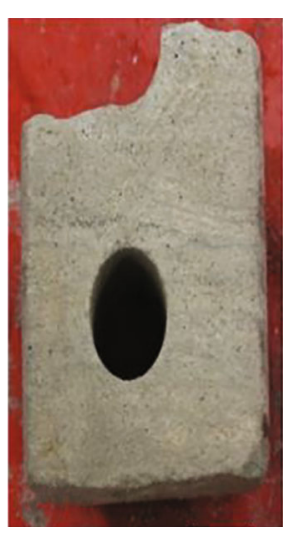

YM702

$4678.43 \mathrm{~m}$

(c)

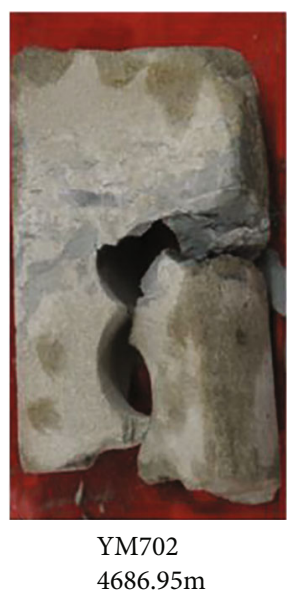

(d)

Figure 4: Core photos of Paleogene sedimentary structural types in Yingmai 7 block: (a) parallel bedding; (b) oblique bedding; (c) wavy bedding; (d) scour surface.

3.1.2. Sedimentary Structure and Particle Size Analysis. The Paleogene Kumugelimu Formation in Yingmai 7 block develops parallel bedding, oblique bedding, wavy bedding, and erosion surface, which are typical characteristics of braided river delta deposition, reflecting unstable sedimentary hydrodynamic conditions.

For parallel bedding, in the coarse silt sandstone and fine sandstone in the $4684.8 \mathrm{~m}$ section of Well YM702, the parallel bedding sometimes has clear laminations and sometimes blurred laminae, showing the depositional characteristics of high flow water flow, which is deposited under the condition of continuous and stable water flow. As a result, they are generally deposited under broad flow conditions, such as the channel flanks at the ends of distributary channels (Figure 4(a)).

For oblique bedding, oblique bedding is developed in the sandstone in the $4676.4 \mathrm{~m}$ section of Well YM702, and the interface between layers is relatively straight. The layer system is composed of many thin layers that are inclined in the same direction, and the thin layer and the layer system interface are oblique. If the adjacent layers are parallel to each other, the medium and fine layers in each layer are inclined in one direction, which is called monoclinic bedding. It is formed when water flows in a single direction, and the sloping direction of its thin layers indicates the downstream direction of water flow and is commonly found in river deposits and other sediments with flowing water (Figure 4(b)).

For wavy bedding, wavy bedding is formed when the hydrodynamic conditions alternate between strong and weak. It is more developed in delta fronts, rivers, tides, and other environments (Figure 4(c)).

For erosion surface, the undulating structural surface formed by the erosion and erosion of the underlying sediment due to the sudden increase of the flow velocity reflects the characteristics of strong hydrodynamics. The sediments on the scour surface are coarser than the underlying sediments and are more developed in the braided river delta environment (Figure 4(d)).
According to the particle size analysis data of Yingmai 7 block, the C-M map of the Paleogene was established. The samples of the C-M map of the Paleogene were concentrated in the QR section, and the reaction sediments were mainly transported by the gradient suspension of the tractive flow (Figure 5). The grain size probability curve of Paleogene braided river delta facies has two segments. The two-stage grain size probability curve is composed of jumping and suspending populations, and the jumping population is the main one, reflecting the transport and deposition mechanism of tractive flow, mainly developed in siltstone and fine sandstone (Figure 6).

3.1.3. Sedimentary Microfacies Division. Through the analysis of rock color, rock mineral composition, rock structure, grain size, and comprehensive analysis of a large number of sedimentary structures in coring wells, the target layer of the Paleogene in the study area is divided into a lakebraided river delta sedimentary system, and the subfacies is divided into a shallow lake and braided river delta fronts. The microfacies are divided into shallow lake mud, underwater distributary channels, and underwater interdistributary bays (Table 2 ).

\subsubsection{Distribution Characteristics of Sedimentary Microfacies.} During the Paleogene sedimentary period, the provenance came from the southeast, and a set of braided river delta frontal deposits developed, and the overall performance from bottom to top was a water-transgressive sedimentary sequence.

During the E2 depositional period, a braided river delta sedimentary system was developed in the Yingmai 7 block. The provenance came from the southeast. The sand bodies were thin, but the lateral continuity was good. As a whole, the sand bodies in the southeast were more developed than those in the northwest. The planar facies distribution is dominated by underwater distributary channels, with mouth bars developed at the front of the underwater distributary channels, subaqueous interdistributary bays developed 


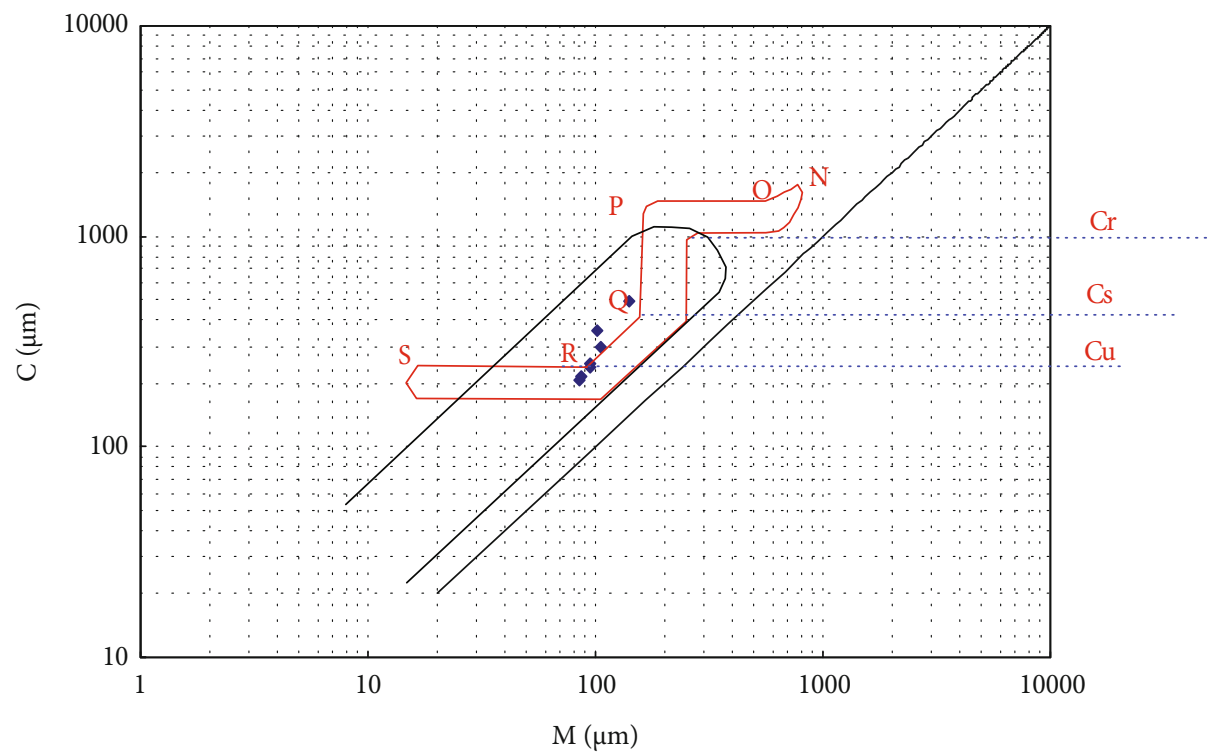

Figure 5: C-M map of Paleogene Kumugelimu Formation reservoir in Yingmai 7 block.

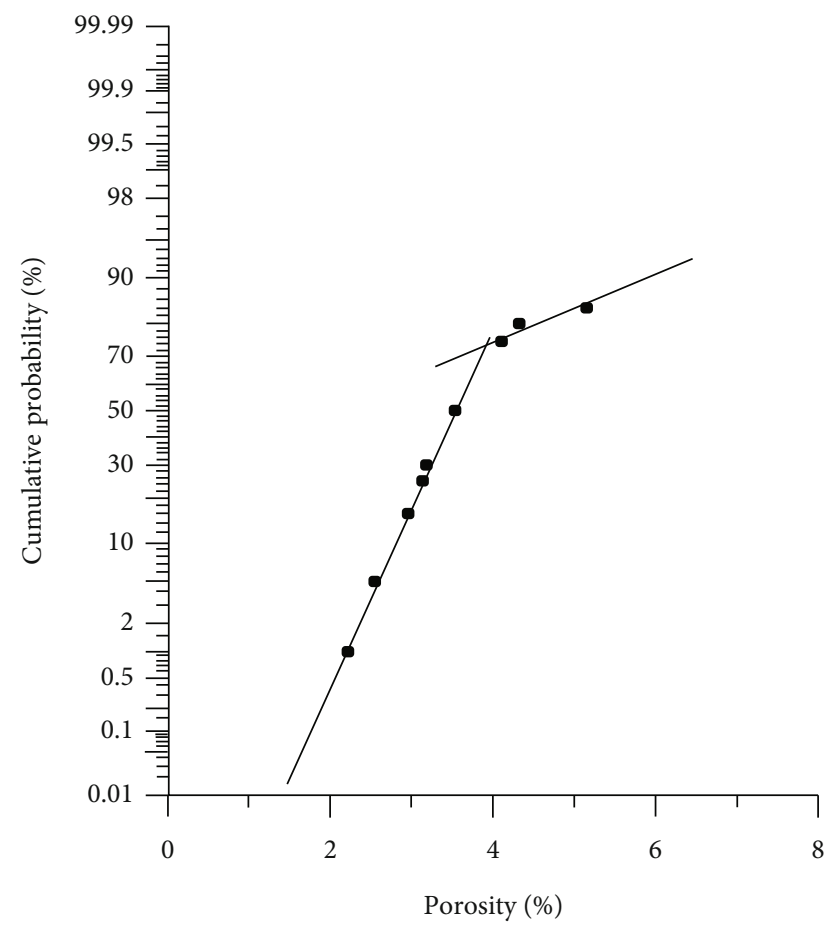

FIGURE 6: Reservoir particle size probability curve of Paleogene Kumugelimu Formation in block Yingmai 7.

locally, and front sheet sand deposits developed outside the mouth bars (Figure 7).

During the E1 depositional period, the provenance came from the southeast. Compared with the E2 period, the water inflow occurred. Affected by water flow in paleosedimentary environment, the main body of the work area was the lake facies coastal shallow lake subfacies, mainly developed shallow lake mud (Figure 8).

\subsection{Reservoir Characteristics}

3.2.1. Microscopic Characteristics of Reservoir. According to the analysis data of the core casting thin section, the pore types of the E2 layer are mainly intergranular pores, and the intergranular porosity ranges from 16.33 to $20.25 \%$ (Table 3).

Through the analysis of the mercury intrusion data of Yingmai 7 block, the capillary pressure curve can be roughly divided into four types: Type A is dominated by high porosity and high permeability, the curve is platform-shaped, the pore throat is well sorted, the displacement pressure low, and the median pore throat radius is greater than $2 \mu \mathrm{m}$. The porosity and permeability of type B are still high, the curve is platform-shaped, the displacement pressure is low, and the median pore throat radius is greater than $1 \mu \mathrm{m}$. The C-type curve is slope-shaped, the displacement pressure is $0.06-0.1 \mathrm{MPa}$, and the median pore throat radius is less than $1 \mu \mathrm{m}$. Type $\mathrm{D}$ is dominated by low porosity and low permeability, the curve is slope-shaped, the pore throat sorting is poor, the displacement pressure is $0.5-3 \mathrm{MPa}$, and the median pore throat radius is less than $0.5 \mu \mathrm{m}$ (Figure 9, Table 4).

\subsubsection{Distribution Characteristics of Reservoir Physical} Properties. According to the statistics of the physical property analysis data of 64 Paleogene cores in Yingmai 7 block, the core analysis porosity is concentrated between 18 and $26 \%$, with an average value of $15.44 \%$. The permeability is concentrated in the range of 80 to $8000 \times 10^{-3} \mu \mathrm{m}^{2}$; the average value is $192.37 \times 10^{-3} \mu \mathrm{m}^{2}$. The Paleogene target layers belong to mesoporous and medium permeability reservoirs (Figures 10 and 11; the reference standard is SY/T 6285-1997).

The Paleogene has obvious upward variation characteristics. The porosity distribution range of E2 layer is 
TABLE 2: Sedimentary microfacies division of Yingmai 7 block.

\begin{tabular}{lccc}
\hline Formation & Face & Sedimentary facies & Mub \\
\hline & Lake & Shallow lake & Shallow lake mud \\
E & Braided river delta & Braided river delta front & Underwater distributary channel \\
& & & Underwater bay \\
\hline
\end{tabular}

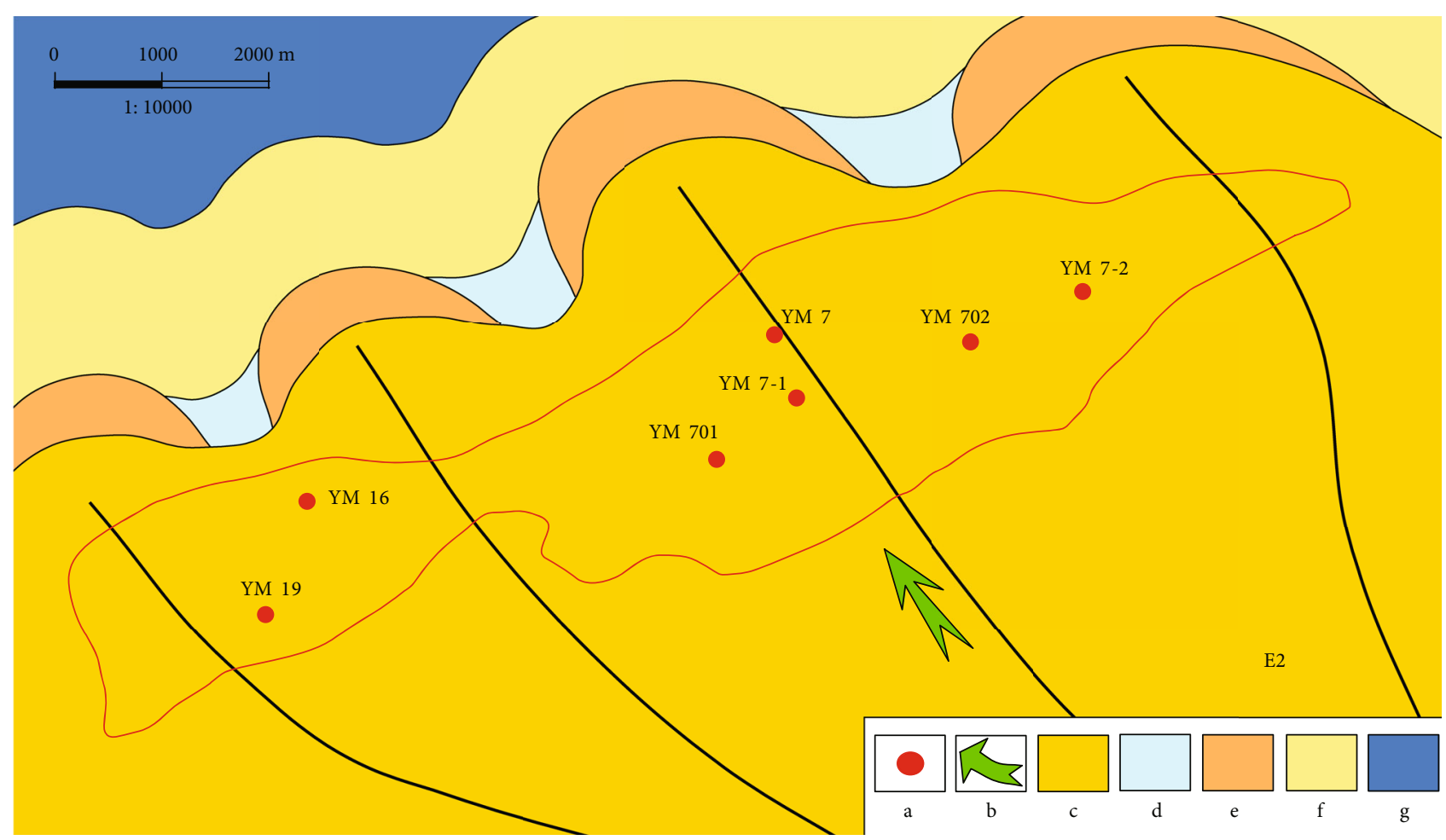

FIgURE 7: Plane distribution of sedimentary microfacies of layer E2 in Yingmai 7 block: (a) well location; (b) provenance direction; (c) underwater distributary channel; (d) underwater distributary bay; (e) mouth bar; (f) front edge sheet sand; (g) shallow lake mud.

$13.06-25.00 \%$ with the average value of $21.80 \%$, and the permeability distribution range is $4.75-6829.40 \times 10^{-3}$ $\mu \mathrm{m}^{2}$ with the average value of $381.54 \times 10^{-3} \mu \mathrm{m}^{2}$. The porosity distribution range of $\mathrm{E} 1$ layer is $8.03 \sim 10.13 \%$, the average value is $9.08 \%$, the permeability distribution range is $2.54-4.27 \times 10^{-3} \mu \mathrm{m}^{2}$, and the average value is $3.20 \times 10^{-3} \mu \mathrm{m}^{2}$ (Table 5).

According to the statistics of porosity and permeability explained by logging in Yingmai 7 block, the variation range of Paleogene porosity is $14.50-24.60 \%$, with an average value of $20.46 \%$. The variation range of permeability is $58.60-2482.50 \times 10^{-3} \mu \mathrm{m}^{2}$, and the average value is $599.45 \times 10^{-3} \mu \mathrm{m}^{2}$, which indicates that the plane porosity and permeability of the Paleogene reservoirs are quite different, and the physical properties are highly nonuniform (Table 6).
The average porosity of the E1 layer is $19.46 \%$, and the average permeability is $432.71 \times 10^{-3} \mu \mathrm{m}^{2}$. The minimum values of porosity and permeability are $14.53 \%$ and $58.63 \times$ $10^{-3} \mu \mathrm{m}^{2}$ of Well YM701, respectively. The plane distribution of porosity and permeability contours is controlled by sedimentation and sand body distribution shape, and the plane contours are densely distributed, reflecting the large difference in plane physical properties of this layer (Figure 12).

The average porosity of the E2 layer is $21.46 \%$, and the average permeability is $766.19 \times 10^{-3} \mu \mathrm{m}^{2}$. The minimum values of porosity and permeability are $16.47 \%$ and $155.73 \times$ $10^{-3} \mu \mathrm{m}^{2}$ in Well YM16, respectively. The plane distribution of porosity and permeability contours is controlled by sedimentation and sand body distribution, and the plane contours are unevenly distributed, reflecting the large difference in 


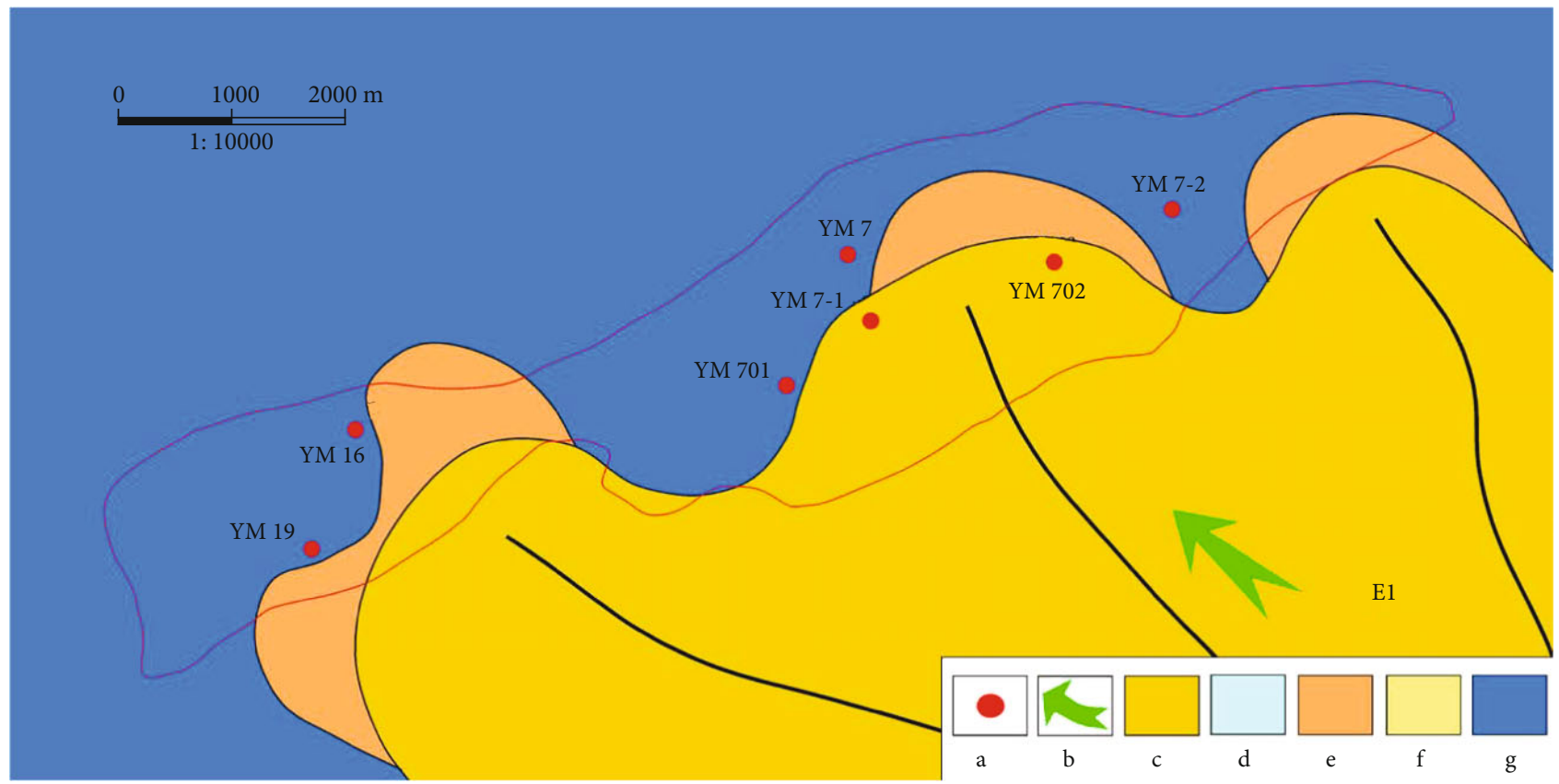

FIgURE 8: Plane distribution map of sedimentary microfacies of layer E1 in Yingmai 7 block: (a) well location; (b) provenance direction; (c) underwater distributary channel; (d) underwater distributary bay; (e) mouth bar; (f) front edge sheet sand; (g) shallow lake mud.

TABLE 3: Statistics of reservoir pore characteristics in block Yingmai 7.

\begin{tabular}{lccccc}
\hline \multirow{2}{*}{ Formation } & \multirow{2}{*}{ Number of samples } & \multicolumn{2}{c}{ Interparticle pores, $\%$} & \multirow{2}{*}{ Mold pores, \% } & Intraparticle pores, \% \\
\hline E2 & 10 & 5.44 & 10.89 & $1 \sim 2$ & $1 \sim 2$ \\
\hline
\end{tabular}

plane physical properties of this layer, but the difference is smaller than that of E1 (Figure 13).

\subsection{Reservoir Heterogeneity}

3.3.1. Reservoir Heterogeneity between Layers. In this study, the following parameters are mainly used to evaluate the heterogeneity of reservoir physical properties.

Sand ratio refers to the ratio of the total thickness of sandstone on the vertical section to the total thickness of the formation, expressed as a percentage, equivalent to the ratio of sand to ground (\%). According to the stratum thickness of Yingmai 7 block and the statistical results of sand body thickness interpreted by logging, the sand-to-ground ratio is calculated. The average total thickness of the two Paleogene layers in block Yingmai 7 is $63.09 \mathrm{~m}$, the average total sandstone thickness is $33.55 \mathrm{~m}$, and the average sandto-ground ratio is 0.51 (Table 7 ).

For interlayer permeability heterogeneity, the physical property statistics show that the minimum permeability of each sublayer of Paleogene in Yingmai 7 block is $58.60 \times$ $10^{-3} \mu \mathrm{m}^{2}$, the maximum value is $2482.50 \times 10^{-3} \mu \mathrm{m}^{2}$, and the average value is $645.50 \times 10^{-3} \mu \mathrm{m}^{2}$. The permeability difference between layers is larger, indicating that the degree of heterogeneity between layers is strong.
Formula (1) and formula (2) show the calculation of permeability coefficient of variation (VK):

$$
\begin{gathered}
V_{K}=\frac{\delta}{\bar{K}}, \\
\delta=\sqrt{\sum_{i=1}^{n-1} \frac{\left(k_{i}-\bar{k}\right)^{2}}{n} .} .
\end{gathered}
$$

In the formula, $K$ is the average permeability of the core, $10^{-3} \mu \mathrm{m}^{2} ; k_{i}$ is the permeability of each core sample, $10^{-3} \mu \mathrm{m}^{2} ; \delta$ is the permeability variance, $10^{-3} \mu \mathrm{m}^{2}$; and $n$ is the number of core samples.

Generally, when $V_{K}<0.5$, it means that the degree of heterogeneity is weak; when $V_{K}$ is 0.5 to 0.7 , it means that the degree of heterogeneity is moderate; when $V_{K}>0.7$, it means that the degree of heterogeneity is strong.

The calculation of the rush factor (TK) is shown in formula (3):

$$
T_{K}=\frac{K_{\max }}{\bar{K}}
$$




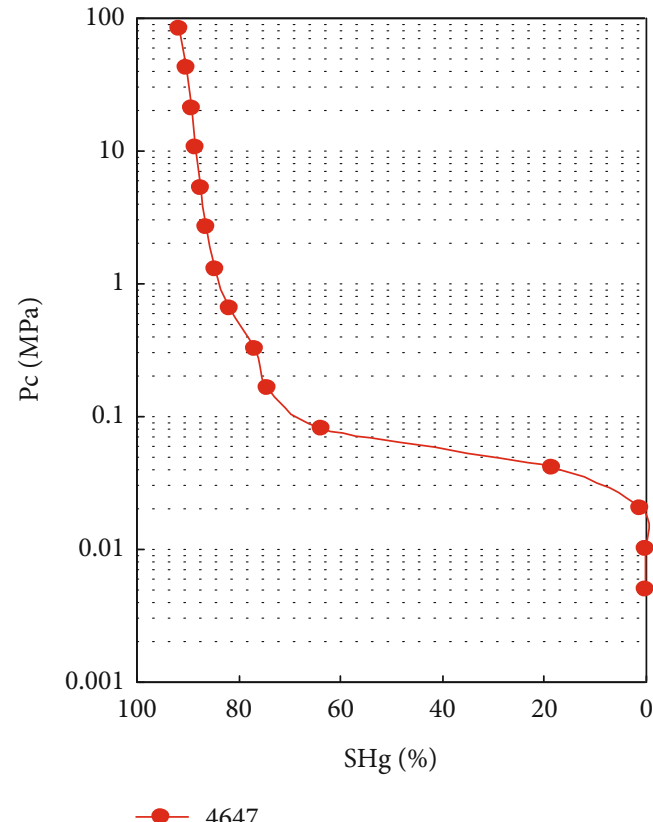

(a)

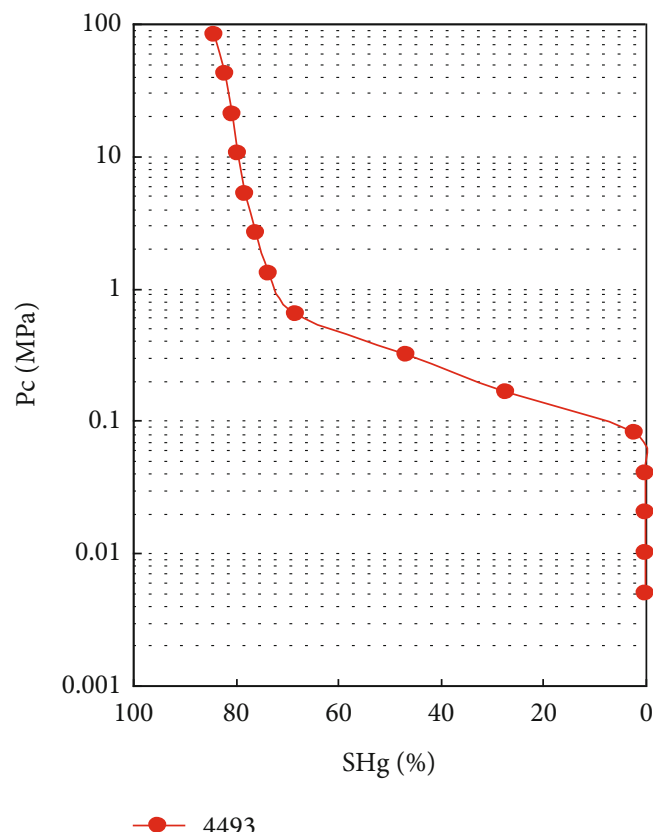

(c)

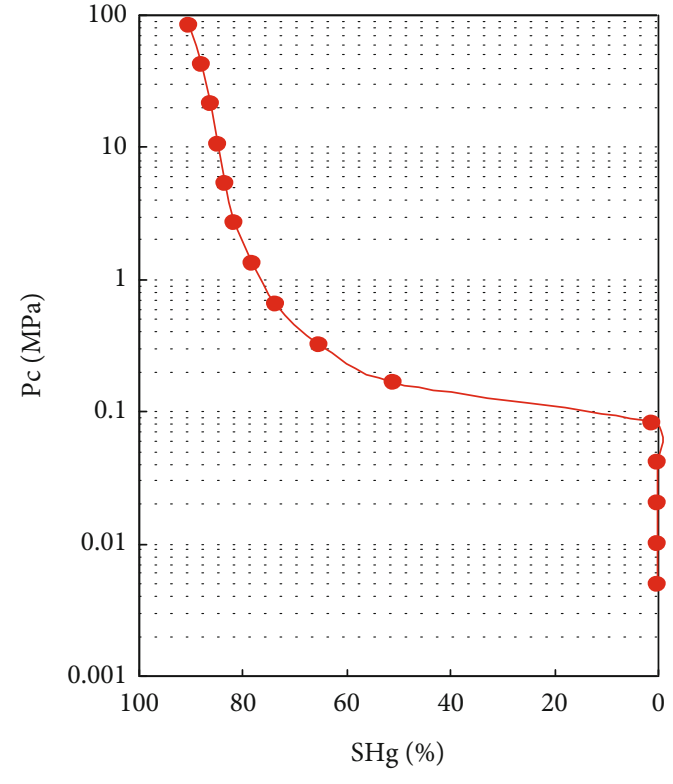

(b)

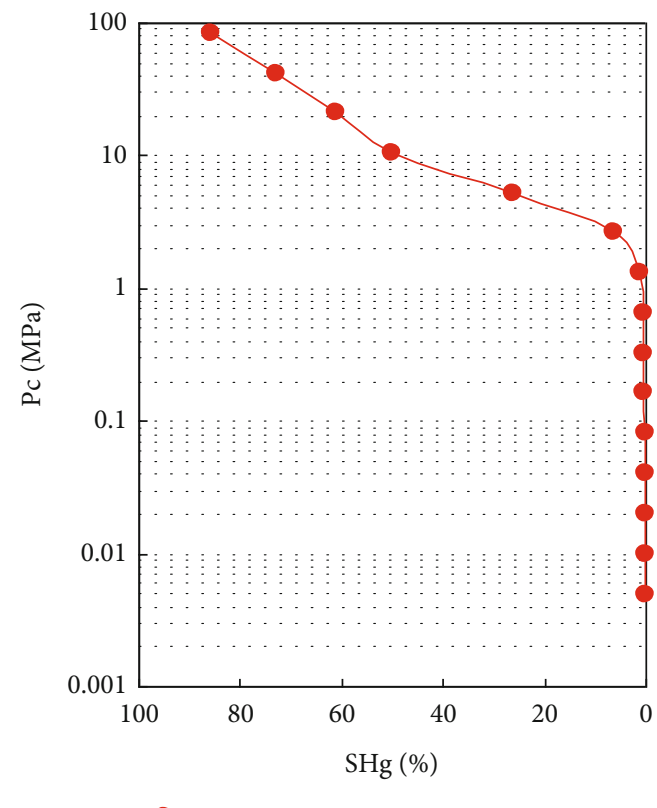

(d)

Figure 9: Typical mercury intrusion curve of Yingmai 7 block.

TABle 4: Statistics of the average pore structure characteristic parameters of block Yingmai 7.

\begin{tabular}{lcccccccc}
\hline Type & $\begin{array}{c}\text { Number of } \\
\text { samples }\end{array}$ & $\begin{array}{c}\text { Permeability, } \\
10^{-3} \mu \mathrm{m}^{2}\end{array}$ & $\begin{array}{c}\text { Porosity, } \\
\%\end{array}$ & $\begin{array}{c}\text { Displacement } \\
\text { pressure, MPa }\end{array}$ & $\begin{array}{c}\text { Median } \\
\text { pressure, MPa }\end{array}$ & $\begin{array}{c}\text { Sorting } \\
\text { coefficient }\end{array}$ & $\begin{array}{c}\text { Maximum throat } \\
\text { size, } \mu \mathrm{m}\end{array}$ & $\begin{array}{c}\text { Median throat } \\
\text { size, } \mu \mathrm{m}\end{array}$ \\
\hline A & 39 & 509.60 & 20.37 & 0.03 & 0.47 & 2.26 & 34.18 & 3.78 \\
B & 11 & 145.07 & 18.70 & 0.07 & 0.43 & 1.91 & 15.84 & 1.80 \\
C & 5 & 67.70 & 14.88 & 0.07 & 0.49 & 2.43 & 10.85 & 0.83 \\
D & 2 & 1.49 & 7.25 & 1.96 & 23.05 & 1.68 & 0.42 & 0.02 \\
\hline
\end{tabular}




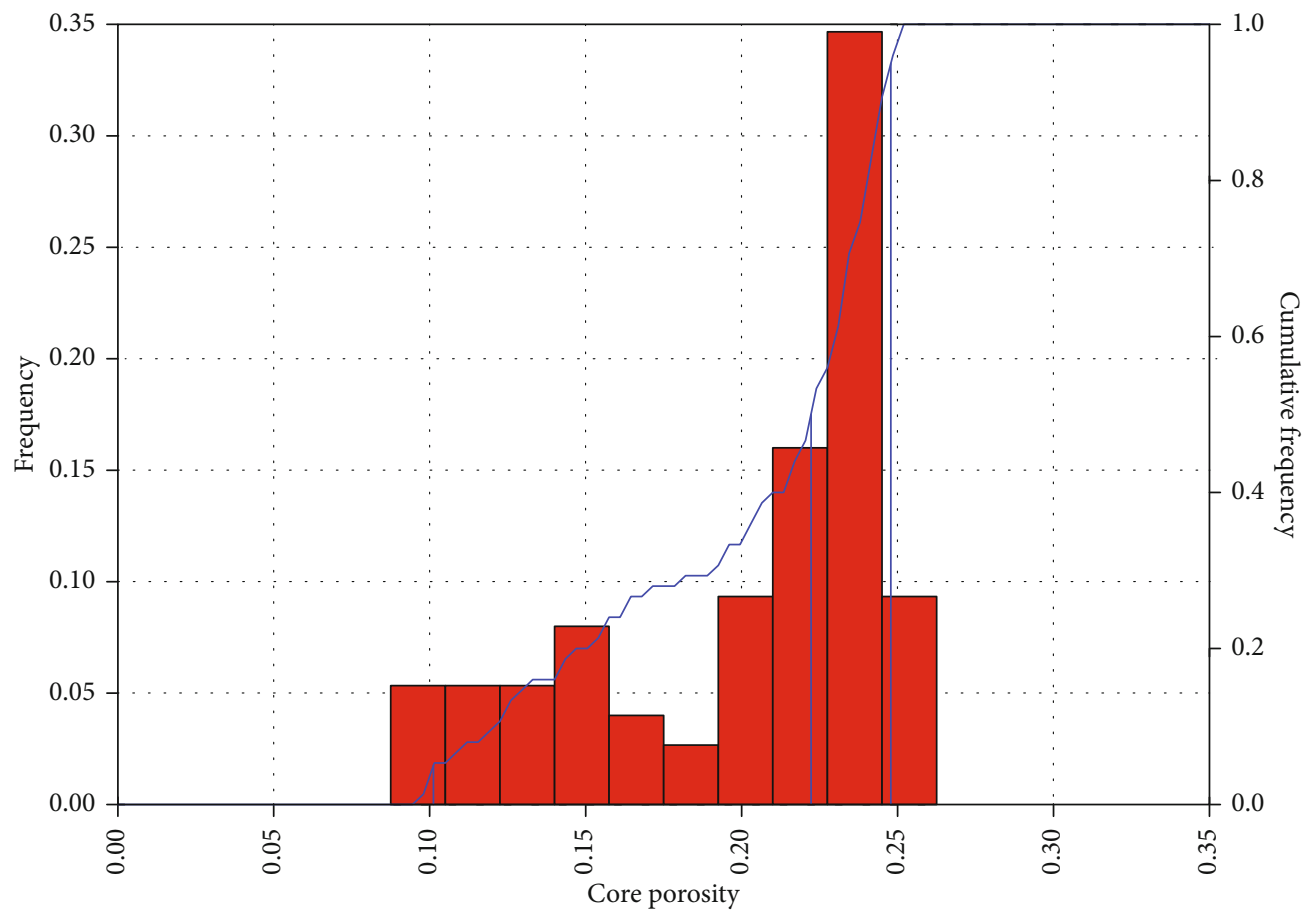

FIgURE 10: Histogram of frequency distribution of porosity in Paleogene core analysis of block Yingmai 7.

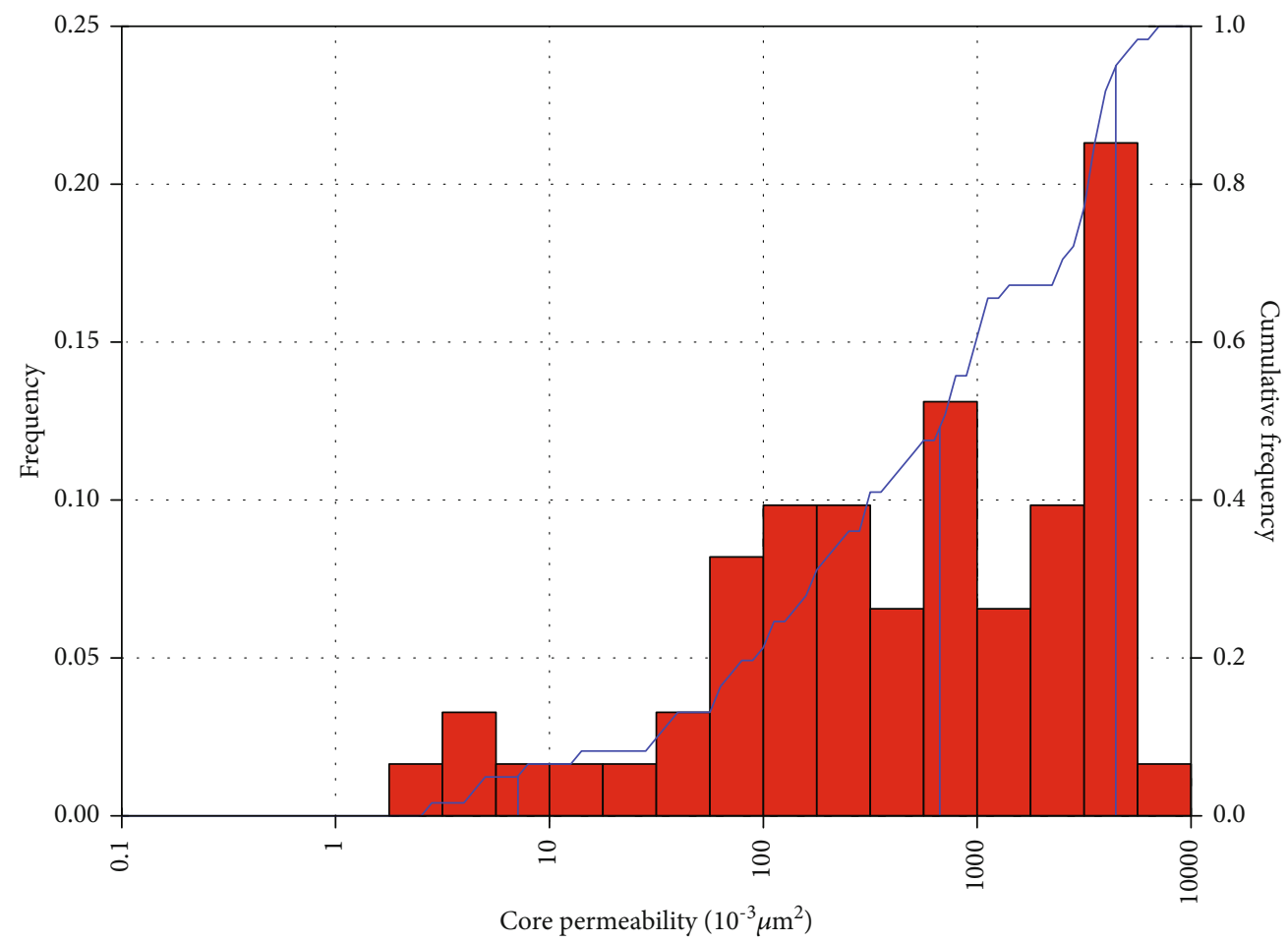

FIGURE 11: Histogram of permeability frequency distribution of Paleogene core analysis in Yingmai 7 block. 
TABLE 5: Reservoir physical property statistics for core analysis of block Yingmai 7.

\begin{tabular}{|c|c|c|c|c|c|c|c|}
\hline \multirow{2}{*}{ Formation } & \multirow{2}{*}{ Sample number } & \multicolumn{3}{|c|}{ Porosity, \% } & \multicolumn{3}{|c|}{ Permeability, $10^{-3} \mu \mathrm{m}^{2}$} \\
\hline & & Maximum & Minimum & Mean & Maximum & Minimum & Mean \\
\hline$\overline{\mathrm{E} 1}$ & 2 & 8.03 & 10.13 & 9.08 & 2.54 & 4.27 & 3.20 \\
\hline $\mathrm{E} 2$ & 62 & 13.06 & 25.00 & 21.80 & 4.75 & 6829.40 & 381.54 \\
\hline
\end{tabular}

TABLE 6: Reservoir physical property statistics for logging interpretation in block Yingmai 7.

\begin{tabular}{lccccc}
\hline Formation & Maximum & $\begin{array}{c}\text { Porosity, } \% \\
\text { Minimum }\end{array}$ & Mean & Maximum & $\begin{array}{c}\text { Permeability, } 10^{-3} \mu \mathrm{m}^{2} \\
\text { Minimum }\end{array}$ \\
\hline E1 & 14.50 & 22.00 & 19.46 & 58.60 & 2482.50 \\
E2 & 16.50 & 24.60 & 21.46 & 155.70 & 2482.50 \\
E & 14.50 & 24.60 & 20.46 & 58.60 & 766.19 \\
\hline
\end{tabular}

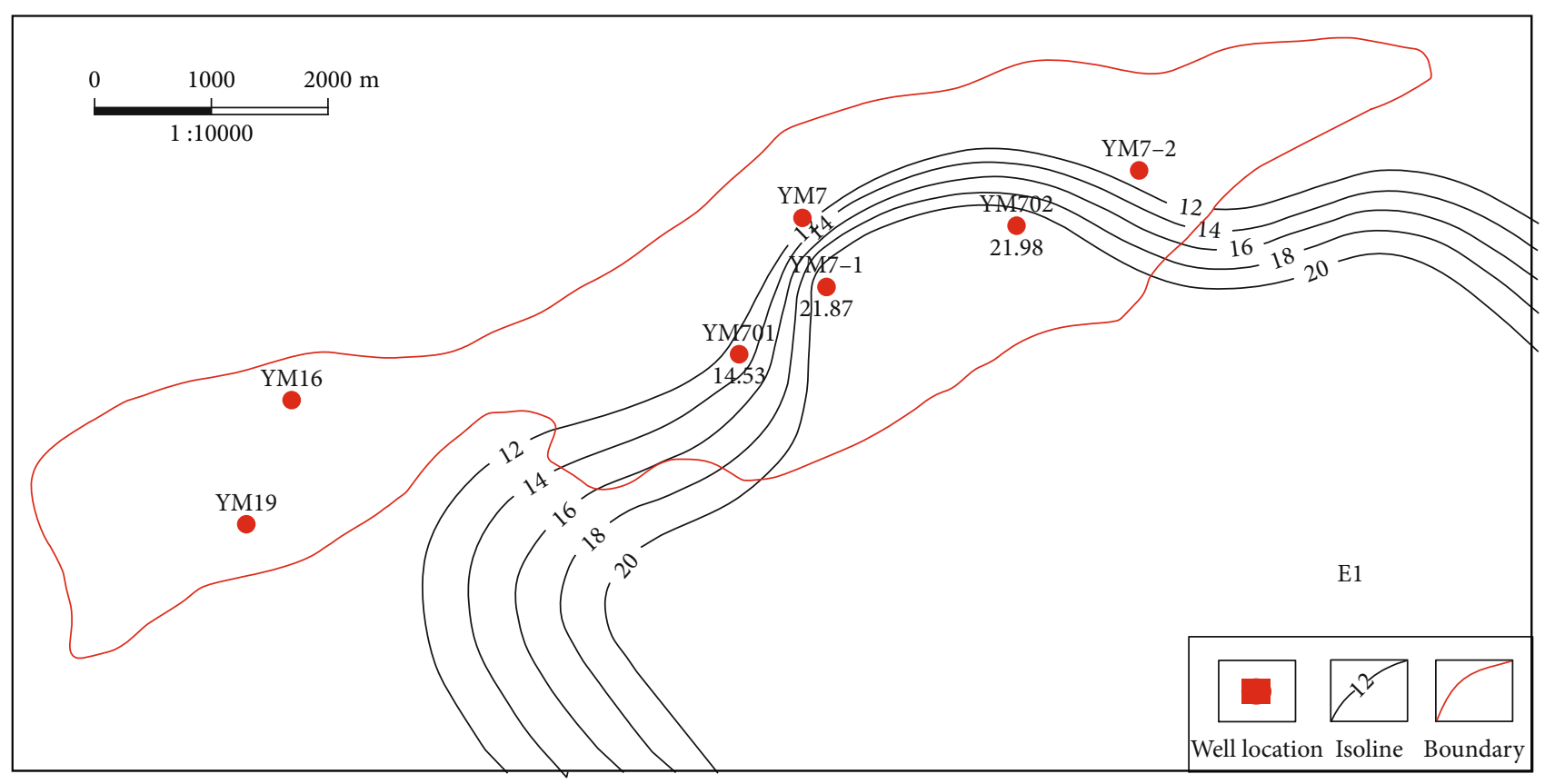

FIGURE 12: Contour map of porosity in the E1 layer of block Yingmai 7.

In the formula, $K_{\max }$ is the maximum permeability of the core sample, $10^{-3} \mu \mathrm{m}^{2}$.

When $T_{K}<2$, it means that the degree of heterogeneity is weak; when $T_{K}$ is 2 to 3 , it means that the degree of heterogeneity is moderate; when $T_{K}>3$, it means that the degree of heterogeneity is strong.

The difference $\left(J_{K}\right)$ calculation is shown in formula (4):

$$
J_{K}=\frac{K_{\max }}{K_{\min }}
$$

In the formula, $K_{\min }$ is the minimum permeability of the core sample, $10^{-3} \mu \mathrm{m}^{2}$.
When $J_{k}<20$, it means that the degree of heterogeneity is weak; when $J_{k}$ is $20-30$, it means that the degree of heterogeneity is moderate; when $J_{k}>30$, it means that the degree of heterogeneity is strong.

Through the calculation of the heterogeneity parameters of the interlayer permeability in the Yingmai 7 block, the coefficient of variation of the Paleogene permeability is 1.46, the inrush coefficient is 3.85 , and the gradient is 42.36 , reflecting the characteristics of strong interlayer heterogeneity (Table 8).

3.3.2. Reservoir Heterogeneity. According to the vertical variation of intralayer permeability, the intralayer heterogeneity in this area can be divided into four types, namely, 


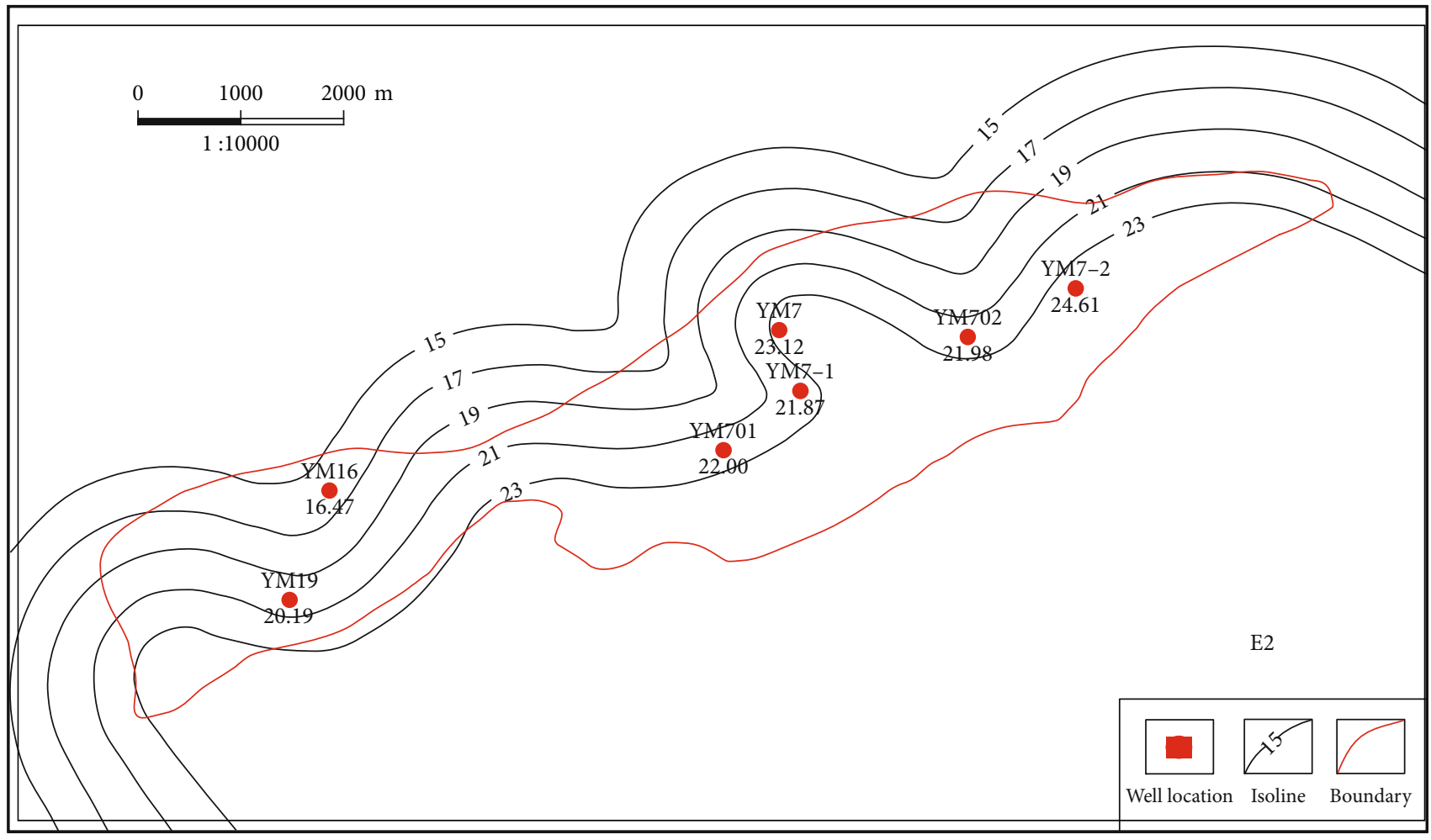

FIGURE 13: Porosity plane contour map of layer E2 in Yingmai 7 block.

positive rhythm type, inverse rhythm type, compound rhythm type, and homogeneous rhythm type. Generally, the permeability heterogeneity of the compound rhythm type is higher, followed by the positive rhythm type, the inverse rhythm type has relatively good homogeneity, and the homogeneous rhythm type has weak permeability heterogeneity.

For positive rhythm type, permeability increases vertically from bottom to top, and the highest permeability segment is distributed in the lower or middle-lower part. The natural gamma curve presents a box-bell shape. The acoustic transit time decreases slightly from bottom to top. The curve does not change much from bottom to top.

For inverse rhythm type, permeability increases from small to large vertically from bottom to top, the highest permeability segment is distributed in the upper or middleupper part, the natural gamma curve presents a funnel-box shape, the acoustic time difference increases slightly from bottom to top, and the resistivity curve decreases slightly from bottom to top.

For compound rhythm type, compound rhythm mainly occurs in thick sand layers (thick single sand layer or thick superimposed sand layer); there are four types of compound rhythms: one is multiphase positive rhythm combination type, the second is multiphase antiarrhythmic combination type, the third is the combination type of inverse rhythmpositive rhythm, and the fourth is the combination type of positive rhythm-inverse rhythm. Multiphase positive rhythm combination is a common type of permeability
TABLE 7: Statistical table of sand-to-ground ratio parameters of Yingmai 7 block.

\begin{tabular}{lccc}
\hline Formation & $\begin{array}{c}\text { Total } \\
\text { thickness, } \mathrm{m}\end{array}$ & $\begin{array}{c}\text { Total thickness of } \\
\text { sandstone, } \mathrm{m}\end{array}$ & Sand ratio \\
\hline E1 & 58.82 & 7.10 & 0.12 \\
E2 & 67.35 & 60.00 & 0.89 \\
Mean & 63.09 & 33.55 & 0.81 \\
\hline
\end{tabular}

combination in thick sand bodies. It is composed of multiple positive permeability rhythms. Natural gamma logging often shows a box-bell combination type, and the resistivity curve slightly reduced from bottom to top, and the sonic curve also slightly reduced.

For homogeneous rhythm type, if the permeability changes vertically without rhythm, it is called homogeneous rhythm.

The Paleogene in Yingmai 7 block developed compound rhythm and inverse rhythm, among which compound rhythm was the main one, which indicated that it had the characteristics of strong intralayer heterogeneity. The intralayer permeability heterogeneity evaluation of the Paleogene reservoir shows that the intralayer permeability gradient is 75.76 , the inrush coefficient is 4.09 , and the variation coefficient is 2.25 , showing a strong degree of heterogeneity (Table 9). 
TABLE 8: Statistics of interlayer heterogeneity parameters of reservoirs in block Yingmai 7.

\begin{tabular}{|c|c|c|c|c|c|c|c|}
\hline \multirow{2}{*}{ Formation } & \multicolumn{4}{|c|}{ Permeability, $10^{-3} \mu \mathrm{m}^{2}$} & \multirow{2}{*}{ Gradation } & \multirow{2}{*}{ Inrush coefficient } & \multirow{2}{*}{ Coefficient of variation } \\
\hline & Maximum & Minimum & & & & & \\
\hline $\mathrm{E} 1$ & 58.60 & 2482.50 & 432.71 & \multirow{2}{*}{645.50} & \multirow{2}{*}{42.36} & \multirow{2}{*}{3.85} & \multirow{2}{*}{1.46} \\
\hline $\mathrm{E} 2$ & 155.70 & 2482.50 & 766.19 & & & & \\
\hline
\end{tabular}

TABLE 9: Statistical table of heterogeneity parameters in the reservoir of Yingmai 7 block.

\begin{tabular}{lcccccc}
\hline \multirow{2}{*}{ Formation } & \multicolumn{2}{c}{ Permeability, $10^{-3} \mu \mathrm{m}^{2}$} & Gradation & Inrush coefficient & Coefficient of variation \\
& Maximum & Minimum & Mean & & 1.33 & - \\
E1 & 2.54 & 4.27 & 3.20 & 1.68 & 6.85 & 2.25 \\
E2 & 4.75 & 711.70 & 103.87 & 149.83 & 4.09 & 2.25 \\
E & 2.54 & 711.70 & 53.53 & 75.76 & & \\
\hline
\end{tabular}

TABLE 10: Reservoir classification evaluation table in Yingmai 7 block of Yingmaili gas field.

\begin{tabular}{|c|c|c|c|c|c|}
\hline \multirow{2}{*}{\multicolumn{2}{|c|}{ Compare items }} & \multicolumn{4}{|c|}{ Reservoir type } \\
\hline & & I & II & III & IV \\
\hline \multicolumn{2}{|c|}{ Thickness of single layer, $\mathrm{m}$} & $\geq 4$ & $4 \sim 2$ & $2 \sim 1$ & $<1$ \\
\hline \multicolumn{2}{|l|}{ Lithology } & $\begin{array}{l}\text { Fine sandstone, } \\
\text { siltstone }\end{array}$ & $\begin{array}{l}\text { Fine sandstone, } \\
\text { siltstone }\end{array}$ & $\begin{array}{l}\text { Fine sandstone, } \\
\text { siltstone }\end{array}$ & Siltstone \\
\hline \multicolumn{2}{|l|}{ Microphase } & $\begin{array}{c}\text { Underwater } \\
\text { distributary channel } \\
\text { estuary dam }\end{array}$ & $\begin{array}{c}\text { Underwater } \\
\text { distributary channel } \\
\text { estuary dam }\end{array}$ & $\begin{array}{c}\text { Underwater } \\
\text { distributary channel } \\
\text { estuary dam }\end{array}$ & $\begin{array}{c}\text { Underwater } \\
\text { distributary channel }\end{array}$ \\
\hline \multirow{3}{*}{$\begin{array}{l}\text { Reservoir } \\
\text { physical } \\
\text { properties }\end{array}$} & Porosity, \% & $\geq 18$ & $18 \sim 15$ & $8 \sim 15$ & $<8$ \\
\hline & Permeability, $10^{-3} \mu \mathrm{m}^{2}$ & $\geq 200$ & $200 \sim 100$ & $100 \sim 2.5$ & $<2.5$ \\
\hline & $\begin{array}{l}\text { Displacement } \\
\text { pressure, } \mathrm{MPa}\end{array}$ & $0.005 \sim 0.04$ & $0.04 \sim 0.08$ & $0.04 \sim 0.3$ & $>0.3$ \\
\hline \multirow{3}{*}{$\begin{array}{l}\text { Mercury } \\
\text { intrusion } \\
\text { parameter }\end{array}$} & Median pressure, $\mathrm{MPa}$ & $0.07 \sim 0.86$ & $0.19 \sim 2.40$ & $0.43 \sim 2.56$ & $>2.25$ \\
\hline & $\begin{array}{l}\text { Median pore throat } \\
\text { radius, } \mu \mathrm{m}\end{array}$ & $1.27 \sim 10.53$ & $0.58 \sim 5.33$ & $0.29 \sim 1.71$ & $<0.29$ \\
\hline & $\begin{array}{l}\text { Maximum pore throat } \\
\text { radius, } \mu \mathrm{m}\end{array}$ & $18.06 \sim 72.06$ & $2.13 \sim 18.15$ & $9.04 \sim 2.23$ & $<2.23$ \\
\hline
\end{tabular}

3.3.3. Reservoir Type Division. According to the sand body thickness, lithology, microfacies, physical properties, and mercury intrusion data, a classification evaluation table of reservoirs in block Yingmai 7 is designated, which is divided into four categories. Type II reservoirs account for $11.7 \%$ of the reservoir types (Table 10). Among them, type I and II reservoirs are high-quality reservoirs for key drilling.

\section{Conclusion}

The Paleogene of Yingmai 7 block is a set of braided river delta sedimentary system, the microfacies is mainly underwater distributary channel, the reservoir rocks are mainly light gray lithic feldspar fine sandstone, and the rock density is loose-medium. The reservoir has average sand-to-ground ratio of $0.51 \%$, strong interlayer and plane heterogeneity, well-developed interlayers, large thickness, and strong intralayer heterogeneity. The average porosity of the reservoir is $15.44 \%$, and the microscopic characteristics of the reservoir are large pore throat radius, low displacement pressure, mainly intergranular pores, and good pore connectivity. The reservoir is a thin-layered mesoporous, medium permeability, large throat, and strongly heterogeneous reservoir.

\section{Data Availability}

The figures and tables used to support the findings of this study are included in the article.

\section{Conflicts of Interest}

The authors declare that they have no conflicts of interest.

\section{Acknowledgments}

The authors would like to show sincere thanks to those techniques who have contributed to this research. 


\section{References}

[1] C. Z. Jia and G. Q. Wei, "Structural characteristics and petroliferous features of Tarim Basin," Chinese Science Bulletin, vol. 47, no. S1, pp. 1-11, 2002.

[2] D. F. He, "Unconformities and oil and gas accumulation in Tarim Basin," Acta Petrolei Sinica, vol. 16, no. 3, pp. 14-21, 1995.

[3] D. G. Liang, S. C. Zhang, J. P. Chen, F. Y. Wang, and P. R. Wang, "Organic geochemistry of oil and gas in the Kuqa depression, Tarim Basin, NW China," Organic Geochemistry, vol. 34, no. 7, pp. 873-888, 2003.

[4] H. T. An, H. Y. Li, J. Z. Wang, and X. F. Du, "Tectonic evolution and its controlling on oil and gas accumulation in the northern Tarim Basin," Geotectonica et Metallogenia, vol. 33, no. 1, pp. 142-147, 2009.

[5] T. Jun, "Petroleum exploration history and enlightenment in Tarim Basin," Xinjiang Petroleum Geology, vol. 42, no. 3, p. 272,2021

[6] Y. H. Lu, Z. Y. Xiao, Q. Y. Gu, and Q. C. Zhang, "Geochemical characteristics and accumulation of marine oil and gas around Halahatang depression, Tarim Basin, China," Science in China Series D: Earth Sciences, vol. 51, no. S1, pp. 195-206, 2008.

[7] G. Y. Zhu, X. W. Liu, Y. F. Zhu, J. Su, and K. Wang, "The characteristics and the accumulation mechanism of complex reservoirs in the Hanilcatam area, Tarim Basin," Bulletin of Mineralogy, Petrology and Geochemistry, vol. 32, no. 2, pp. 231-242, 2013.

[8] C. C. Pan, Z. Y. Zhou, S. F. Fan, and Q. L. Xie, “Thermal history of Tarim Basin," Bulletin of Mineralogy, Petrology and Geochemistry, vol. 15, no. 3, pp. 150-152, 1996.

[9] Z. J. Zhao, J. H. Luo, Y. B. Zhang, X. N. Wu, and W. Q. Pan, "Lithofacies paleogeography of Cambrian sequences in the Tarim Basin," Acta Petrolei Sinica, vol. 32, no. 6, pp. 937948, 2011.

[10] L. J. Tang, "Evolution and tectonic patterns of Tarim Basin," Earth Science - Journal of China University of Geosciences, vol. 19, no. 6, pp. 742-754, 1994.

[11] Z. Q. Zhang, J. T. Dou, J. G. Fu, J. Pu, and Y. Z. Wu, "Drilling fluid research for Paleogene strata in Yingmaili area," Petroleum Drilling Techniques, vol. 41, no. 2, pp. 54-58, 2013.

[12] S. L. Su, X. Q. Pang, B. S. Zhang, H. Sun, and A. Y. Sun, "Marine oil source of the Yingmaili Oilfield in the Tarim Basin," Marine and Petroleum Geology, vol. 68, pp. 18-39, 2015.

[13] Y. Y. Zhang and X. Q. Luo, "K-Ar dating authigenic illites and the hydrocarbon accumulation history of the Silurian bituminous sandstone reserviors in the Yingmaili area, Tarim Basin," Petroleum Exploration and Development, vol. 38, no. 2, pp. 203-210, 2011.

[14] Z. M. Wang and A. D. He, "Hydrocarbon enrichment, and, exploration domains in mid-western Tabei uplift, Tarim Basin," Xinjiang Petroleum Geology, vol. 30, pp. 153-156, 2009.

[15] L. D. Sun, X. Y. Zhou, and G. L. Wang, "Contributions of petroleum geology and main directions of oil-gas exploration in the Tarim Basin," Chinese Journal of Geology, vol. 40, no. 2, pp. 167-178, 2005.

[16] N. N. Zhang, D. F. He, F. Y. Sun, and B. L. Gui, "Formation mechanism and structural model of Yingmai 2 anticline in Tabei uplift, Tarim Basin," Chinese Journal of Geology, vol. 48, no. 1, pp. 133-148, 2013.
[17] J. F. Chen, Y. C. Xu, and D. F. Huang, "Geochemical characteristics and origin of natural gas in Tarim Basin, China," AAPG Bulletin, vol. 84, no. 5, pp. 591-606, 2000.

[18] F. P. Wang, Z. Y. Wang, X. Y. Liu, and D. S. Wu, "Characters of Triassic-Jurassic reservoirs in northern Tarim Uplift," Oil \& Gas Geology, vol. 16, no. 3, pp. 277-284, 1995. 